\title{
Das racionalidades da História: o Império do Brasil em perspectiva teórica ${ }^{1}$
}

On History's Rationalities: The Empire of Brazil in a Theoretical Perspective

\section{Maria Fernanda Vieira Martins \\ Professora adjunta no \\ Departamento de História da Universidade Federal de Juiz de Fora (ICH/IFJF - Juiz de Fora/Brasil) e-mail: fernandavmartins@uol.com.br}

\section{Resumo}

0 objetivo principal desses comentários é analisar o modelo e 0 instrumental teórico utilizado no artigo apresentado por Ricardo Salles no que concerne à sua aplicação a um processo específico, a formação e consolidação do estado imperial brasileiro e suas bases de poder no século XIX.

\section{Abstract}

The main purpose of these notes is to analyze the theoretical instruments and model used in Ricardo Salles' article regarding its application to a specific process: the formation and consolidation of the Brazilian Imperial State and the foundations of its power in the Nineteenth Century.

\section{Palavras-chave}

Brasil Imperial, elites, formação do Estado

\section{Keywords}

Imperial Brazil, elites, State Building contexto do século XIX. Escravidão nacional, classe senhorial e intelectuais na formação do Estado, de Ricardo Salles, apresentado para debate no fórum da revista Almanak. Rio de Janeiro, Museu de Astronomia, 3 de novembro de 2011. 
2

Refiro-me, basicamente, ao debate iniciado com as obras de José Murilo de Carvalho, $A$ Construção da ordem/Teatro de sombras, tese defendida originalmente na Universidade de Stanford em 1974 e publicados no Brasil pela primeira vez em 1980 e em 1988, respectivamente, e de IImar R. Mattos, 0 Tempo Saquarema, tese de doutorado apresentada ao Departamento de História da Faculdade de Filosofia, Letras e Ciências Humanas da Universidade de São Paulo, em 1985. Ambos os trabalhos tornaram-se referências fundamentais exatamente por abrirem o debate acerca da formação do Estado imperial e do papel das elites nessa sociedade e lançarem novas perspectivas de abordagem sobre o tema.
0 trabalho que ora se apresenta tem o inquestionável mérito de trazer à superfície algumas questões que seguem insatisfatoriamente exploradas no que concerne ao Brasil do II Reinado, demonstrando como ainda estamos longe de compreender, de fato, esse antigo Império. Mérito também tem o de retomar a discussão teórica acerca da formação do Estado Imperial Brasileiro, necessidade cada vez mais evidente com a ampliação das pesquisas na área e as possibilidades suscitadas por novas abordagens e metodologias.

Ao comentar-se artigo tão longo e de ampla abrangência, diversas possibilidades de abordagem podem ser consideradas. Entretanto, optei por me concentrar em algumas questões específicas, de natureza teórica, exatamente por reconhecer a importância dessa discussão no cenário atual da historiografia brasileira.

0 texto recupera discussão típica da historiografia dos anos 1980 que, inclusive, muitos julgavam, ou julgam, superada. ${ }^{2}$ Mas exatamente pelo fato de estar sendo trazida de volta, seria natural esperar que viesse acompanhada de algumas novidades, seja do ponto de vista da abordagem, da metodologia ou das próprias fontes, mediante a incorporação de novos corpos documentais ou novo tratamento sobre a documentação tradicional.

Entretanto, na ausência dessas novidades a argumentação teórica corre o risco de encerrar-se nela mesma, simplesmente porque nada parece muito diferente daquele debate sobre a formação do Estado brasileiro, cerca de 20 e tantos anos atrás. Pessoalmente, não compartilho da visão do autor, baseada em instrumental gramsciniano, e mantenho minhas dúvidas sobre sua aplicabilidade ao caso brasileiro no século XIX. Na verdade, não me atrai a perspectiva de partir de modelos teóricos estruturantes que, em geral, relegam a segundo plano as fontes, os indivíduos e as dinâmicas dos eventos e processos que elas revelam, exatamente por se construirem sobre categorias de análise que, a meu ver, a priori, fecham e excluem caminhos na investigação histórica, como entendo o trabalho em discussão.

Mas essa não é a questão; em princípio, diferentes modelos e abordagens teóricas podem e devem ser testadas sobre diferentes conjunturas, sem prejuizo para o bom e saudável debate historiográfico. 0 que deve importar é a forma como esses modelos são aplicados e utilizados e até que ponto são capazes de sustentar argumentação sólida e consistente, que efetivamente contribua para o entendimento de um processo que, como afirmei acima, ainda carece de debate e investigações.

0 maior desconforto provocado por modelos teóricos estruturantes, na forma como o que aqui se apresenta, é a necessária atribuição de uma racionalidade única à história e seus atores, um certo determinismo nas ações e no desenrolar dos acontecimentos, dados por comportamentos típicos de classes, grupos de pressão, partidos etc. Contrariando essa visão, no entanto, não são poucos os historiadores e correntes historiográficas que, atualmente, partem do princípio de que a racionalidade, quando existente, são racionalidades, são múltiplas, e em boa medida obedecem a circunstâncias ou conjunturas, embora obviamente sempre moldadas por sistemas de crenças, culturas, hábitos etc. Tais usos dos modelos tendem a deixar de lado a história que se revela com a aproximação do olhar e quando o investigador se concentra nos indivíduos, em suas ações, em suas escolhas e discursos, ou melhor, nas regras, normas e crenças que estas trajetórias revelam sobre uma dada sociedade; nos elementos cotidianos que só surgem como indícios e pistas de um passado que precisa ser, de uma forma ou de outra, reconstituído pelos registros que deixou. 
Entre diversos outros, cito AGGIO, Alberto (org.). Gramsci. A vitalidade de um pensamento. São Paulo: Unesp, 1998 (Parte III: Gramsci, a América Latina e o Brasil) e BOBBI0, Norberto. Ensaios sobre Gramsci e o conceito de sociedade civil. São Paulo: Paz e Terra, 1999 (capítulo III: Gramsci e a teoria política).

4

GRAMSCI, Antonio. Cadernos do cárcere. Vol.3. Rio de Janeiro: Civilização Brasileira, 2000. p.41.

5

Idem.Concepção dialética da História. Rio de Janeiro: Civilização Brasileira, 1981. p.100.
Por serem prévios à pesquisa e por partirem da ideia de uma racionalidade atribuída à história, esses modelos precisam, geralmente, ser impostos no que chamarei de realidade, na ausência de termo mais adequado. É verdade que sempre é possivel encaixar, sem dúvida. 0 problema, no entanto, são as lacunas e as bordas que são deixadas de lado, e que acabam sendo tratadas como periféricas, marginais e residuais, ou percebidas como fenômenos isolados que não comprometeriam as conclusões macroestruturais.

0 texto parte de muitas afirmativas que a ausência da apresentação de um corpo de fontes sistemático ou sistematizado nos autoriza a atribuir exclusivamente ao modelo teórico e, por essa razão, é nele e nas certezas apresentadas que se concentram minhas amistosas provocações. Uma primeira questão relevante a ser abordada refere-se aos conceitos utilizados, às categorias centrais de análise, portanto, ao próprio modelo de interpretação. 0 artigo parte de consensos em torno de conceitos fundamentais como conservador, hegemonia, classe senhorial, saquarema, intelectuais etc. Nenhum deles, me parece, é satisfatoriamente problematizado, nem em sua conceitualização propriamente dita, nem no tempo, isto é, não se leva em consideração as transformações em curso ao longo do século XIX.

Isso talvez se torne um pouco mais complicado, como o próprio autor já aponta, no caso dos conceitos gramscinianos, dados os tradicionais debates quanto à sua utilização externa ao ambiente para os quais foram formulados, ou seja, às sociedades capitalistas centrais do "Ocidente". Não tenho muito a acrescentar aos que já fizeram essas e outras ponderações com muito maior riqueza, propriedade e conhecimentos, mas gostaria de retomar alguns pontos. ${ }^{3}$ Para Gramsci, hegemonia corresponde ao predomínio de certo grupo ou fração de classe sobre o conjunto da sociedade nacional. 0 Estado é, segundo essa formulação, o organismo próprio de um grupo destinado a criar as condições favoráveis à máxima expansão do próprio grupo ${ }^{4}$ e o que possibilita essa expansão é não ser identificado com os interesses exclusivos dos grupos beneficiados, mas como expressão de toda a sociedade. Além disso, seguindo as palavras do próprio Gramsci,

\footnotetext{
Mas, a partir do momento em que um grupo subalterno torna-se realmente autônomo e hegemônico, criando um novo tipo de Estado, nasce concretamente a exigência de construir uma nova ordem intelectual e moral, isto é, um novo tipo de sociedade e, conseqüentemente, a exigência de elaborar os conceitos mais universais, as mais refinadas e decisivas armas ideológicas. ${ }^{5}$
}

A rigor, precisariamos nos convencer de que o projeto e interesses desse grupo especifico, a chamada classe senhorial, além de subalterno em algum momento de sua história, poderia ser aceito como expressão de toda a sociedade. Gramsci aponta, e esse aspecto é fundamental ao seu modelo de interpretação, a construção de uma nova ordem intelectual e moral, a autonomização de um grupo subalterno, uma formação social emergente - enfim, a mudança -, de onde viriam os intelectuais orgânicos. Nesse sentido, caberia perguntar o que é realmente novo no Brasil oitocentista do II reinado, no que concerne a esses grupos, que nos parecem tão tradicionais, quais seriam os conceitos mais universais, as mais refinadas e decisivas armas ideológicas? Seria a promessa de manutenção da escravidão e da grande propriedade, ou seja, paradoxalmente, a não-mudança? Para Gramsci,

Uma das mais marcantes características de todo grupo social que se desenvolve no sentido do domínio é a sua luta pela assimilação e pela conquista ideológica 
Ver GRAMSCl, Antonio. Cadernos do Cárcere. Op. Cit. Vol.5, 2005

Ibidem, Vol.3, p.47-49. dos intelectuais tradicionais, assimilação e conquista que são tão mais rápidas e eficazes quanto mais o grupo em questão elaborar simultaneamente seus próprios intelectuais orgânicos. ${ }^{6}$

Mas se esse grupo saquarema se identifica com a mudança, quem seriam os representantes da continuidade histórica, os intelectuais tradicionais, que precisam ser assimilados? Gramsci refere-se à hegemonia de um grupo social sobre a sociedade nacional, exercida através das chamadas organizações privadas (Igreja, sindicatos, escolas, etc.), e seria exatamente a sociedade civil o lugar de atuação dos intelectuais. ${ }^{7}$ Assim, caberia a estes a função de construir a homogeneidade de uma classe ou grupo social e o exercício da direção moral e intelectual, não apenas no interior de uma classe, mas para o conjunto da sociedade, na busca da produção e obtenção de consenso. ${ }^{8}$

Assim, fundamental à noção de hegemonia é a ideia de sociedade civil - que junto com a sociedade política forma o chamado Estado ampliado-, pois é nesse âmbito que se constrói a hegemonia e a nova direção moral e intelectual, via a ação dos intelectuais orgânicos. Não intenciono discutir a existência ou não de uma sociedade civil no Brasil imperial, mas creio que sua importância e centralidade para o modelo teórico utilizado pelo autor torna necessária a problematização dessa noção. Seria importante analisar a que tipo de sociedade civil o autor se refere, considerandose, inclusive, os diferentes contextos políticos vividos por essa sociedade. Então, como pensar a construção dessa hegemonia pelos intelectuais orgânicos, se não sabemos o que o autor considera como sociedade civil?

Deixando de lado o modelo teórico no seu sentido mais amplo, enfrentemos aqui outro problema que, do ponto de vista mais pragmático, me parece ainda mais importante a ser discutido, ou seja, como lidar com os demais conceitos que permeiam o texto.

Creio ser importante fazer aqui uma pergunta central, que certamente causará algum estranhamento: será que o termo saquarema prescinde de uma análise conceitual? 0 que explica exatamente sua naturalização pelos historiadores? Ao contrário, creio que ele carece de muitas problematizações. Não podemos nos esquecer de que, diferentemente dos demais conceitos citados acima, ele foi cunhado contemporaneamente, até onde sabemos no contexto das revoltas liberais, ou seja, em uma conjuntura específica, de intensas disputas políticas.

Precisamos, então, nos perguntar - talvez à luz dos privilegiados debates que hoje se popularizam no âmbito da história conceitual ou mesmo nas propostas da chamada escola Collingwoodiana - sobre os sentidos que ele guarda, sobre as identidades e representações que ele encerra, sobre os diferentes contextos de seu emprego em diversas conjunturas ao longo do século XIX; quem usa, como usa, para que usa e por que usa... Caso contrário, me parece, corremos diversos riscos, inclusive o de interiorização de uma noção cujos significados ainda não alcançamos plenamente. A centralidade que 0 termo saquarema assume no texto justifica amplamente essa ponderação.

Outro conceito que precisaria ser problematizado é o de classe senhorial, pois a dificuldade de compreensão dessa noção é o que, creio, explica o seu progressivo abandono pela historiografia mais recente. 0 que é, de fato, a chamada classe senhorial, dita nacional? Antes de nos perguntarmos o que ela abarca, seria, talvez, mais pertinente perguntar o que ela exclui. Se a considerarmos de forma ampliada, ou seja, junto com seus 
intelectuais orgânicos, devemos incluir desde o chefe de gabinete (talvez até de qualquer gabinete, seja liberal ou conservador) até o juiz de paz e 0 professor de primeiras letras do interior das diferentes províncias.

Nesse sentido, o artigo nos faz crer, exatamente pela ausência dessas problematizações, que há uma identificação automática e mecânica entre essas categorias: proprietários de terras, saquaremas, classe senhorial e conservadores. Essas diferenças, e entendo que elas existam, precisam ficar mais claras, de forma a ganhar-se em precisão o que se perde em amplitude.

Cabe ressaltar que ninguém, me parece, duvida do predomínio numérico dos conservadores na política imperial do II reinado. Mas precisamos nos perguntar quantas formas existem no ser conservador. Se nos circunscrevemos ao partido, o problema é grande; mas se deixamos de lado o partido, o problema é ainda maior, pois esse debate anda longe de se esgotar. Não me parece visivel nenhuma clareza no ser conservador e o usual argumento de que "é como eles se viam ou eram vistos" em nada contribui, pois não fizemos ainda esses exercícios de contextualização, como sugere a história conceitual. Naturalmente, podemos usar o termo para classificar uma série de atores sem maiores problemas, mas o grande risco é sua identificação imediata com a classe senhorial, como aparece principalmente no momento em que 0 artigo analisa a composição e direção dos gabinetes. Não identificamos também fazendeiros/proprietários, membros da classe senhorial, historicamente liberais? Até porque, dependendo da província e da conjuntura, eles poderiam compor, inclusive, expressiva maioria.

Quanto aos partidos, sem querer avançar em outra discussão que tende ao interminável, julgo pertinente lembrar algumas questões. 0 advento do próprio sistema parlamentar, seguindo os modelos europeus, impunha a formação dos partidos e a adesão de todos que almejavam a representação em qualquer nivel. Nem sempre, portanto, essas filiações se davam por afinidades ideológicas, o que ajuda a entender a fluidez e inconstâncias dessas identidades partidárias, tanto maior quanto mais nos afastamos da Corte e da Assembléia Geral. Daí, inclusive, nossas dificuldades em entender a composição de ambos os partidos nas diferentes províncias, de comparar e estabelecer padrões sócio-ocupacionais etc. As racionalidades que norteiam as escolhas e opções de atuação político-partidária ai também são outras, são múltiplas, atendem a circunstâncias, rivalidades, sistemas de alianças e conflitos históricos específicos e típicos de uma realidade e de uma dinâmica local/regional. Tais elementos, portanto, tornam-se ainda mais instigantes e significativos como objeto de pesquisa.

Quanto aos chamados fazendeiros, cabe também perguntar se a simples aquisição de terras e escravos transforma necessariamente seus detentores em membros de uma classe. Será que passam automaticamente a compartilhar um mesmo grande projeto político, social, econômico e até cultural? Dependendo do período, da análise da mentalidade econômica e da natureza das fortunas, não estamos autorizados a pensar em alternativas como a busca de status social, em interesses financeiros específicos ou outras coisas do gênero, do ponto de vista dos projetos de vida desses atores? Em geral, há na análise apresentada certa homogeneização que arrisca deixar de lado aspectos importantes quanto à diversidade, aos interesses, discursos, projetos e estratégias do grupo, que, como tal, poderiam nos auxiliar a compreender melhor todo esse processo.

Julgo pertinente abrir aqui um pequeno parêntese, que pode exemplificar e explicar um pouco melhor as dificuldades que encontro na noção 
9

Nunca descobri exatamente quando o Instituto deixou de existir, pois só localizei suas atas até 0 final da década de 1880, mas é sabido que ainda existia nos primeiros anos da República, o que foi atestado por outros documentos e publicações posteriores da própria instituição. Ver MARTINS, Maria Fernanda V. O Imperial Instituto Fluminense de Agricultura: elites, política e reforma agrícola no Segundo Reinado (1860-1897). Dissertação (mestrado em história). Universidade Federal Fluminense, Niterói, 1995. mimeo. de classe senhorial e na identificação de seus intelectuais orgânicos. Há anos atrás, em minha dissertação de mestrado, procurei investigar a atuação do Imperial Instituto Fluminense de Agricultura, sociedade de natureza privada, mas criada por incentivo do imperador que, inclusive, almejava ver criadas associações dessa natureza em todas as províncias do Império. Só vingaram, por curto período, as da Bahia e de Sergipe, além daquela do Rio de Janeiro, muito mais longeva, que sobreviveu, até mesmo, à proclamação da República. ${ }^{9}$

0 Instituto foi declaradamente fundado para discutir os problemas que afetavam a agricultura fluminense, no mesmo ano em que também se criava a própria Secretaria de Estado dos Negócios da Agricultura, Comércio e Obras Públicas, em 1860, desmembrando-se essas áreas de atuação da antiga Secretaria de Estado dos Negócios do Império. Nesse contexto, era recorrente o reconhecimento das crises intermitentes e mesmo da iminência de uma grande crise da agricultura no vale fluminense, como atestam com veemência os primeiros relatórios dos ministros responsáveis pela pasta. Portanto, criava-se o Instituto dando-se Ihe a atribuição de elaborar e debater alternativas para a economia fluminense, particularmente a diversificação da agricultura para além da cultura do café e o enfrentamento do que entendiam como o problema da mão de obra. Em plena década de 1860, portanto, o Instituto assumia claramente posição contrária à utilização da mão-de-obra escrava - a proposta de montagem e manutenção de sua fazenda modelo se baseou nesse princípio - e o grande problema a ser discutido era a dependência da província à monocultura do café.

Mas quem eram essas pessoas que se dispunham a conduzir esse debate nesse momento, a partir da década de 1860? Eram exatamente os fazendeiros do vale fluminense e os intelectuais orgânicos da classe senhorial. Não todos, é verdade; mas seu primeiro presidente foi o conservador marquês de Abrantes, seguido de outro conservador, o ministro do Império e conselheiro de Estado barão e depois visconde de Bom Retiro, que ocupou a presidência do Instituto por 20 anos, desde 1866 até sua morte, em 1886.

$\mathrm{Na}$ diretoria e no conselho fiscal dessa instituição estiveram, por mais de dez anos ou até a morte, diversos nomes dentre os ditos conservadores, tanto políticos como fazendeiros e capitalistas, como o visconde de Barbacena (1861-1890), o visconde de Nogueira da Gama 1861-1897), o conde de Itamaraty (1861-1897), barão de Nova Friburgo (1861-1867), barão do Amparo (1863-1876), barão de Sapucaia (1861-1886), visconde da Cachoeira (1867-1894), barão de Carapebus (1861-1876), conde de Lages (1861-1876), barão de Itambi (1864-1876), e o barão de Rio Bonito (1863-1879).

Além de longa série de nomes dentre os chamados barões do café, presentes na relação de sócios e dos diretores do Instituto, a lista inclui também dois outros nomes emblemáticos da chamada patrulha conservadora, o fazendeiro, deputado e senador Braz Carneiro Nogueira da Costa e Gama, conde de Baependi, vice-presidente do conselho fiscal entre 1861 e 1876, e a própria encarnação da liderança saquarema, Joaquim José Rodrigues Torres, visconde de Itaboraí, presidente do conselho fiscal por dez anos, entre 1861 e 1871, ano de sua morte. Também estavam presentes, progressivamente, aqueles que mais obviamente são entendidos como intelectuais, ou seja, profissionais liberais: médicos, naturalistas, jornalistas, escritores, engenheiros etc.

Esses individuos ocuparam os quadros dirigentes, financiaram, proporcionaram a publicação de uma revista trimestral incrivelmente sólida e 
10

Particularmente importante e sintomático da importância desse cenário político são os intensos e acalorados debates no Parlamento e na Imprensa em torno das polêmicas que acompanharam a adoção e manutenção do Poder Moderador a partir de 1834 e o chamado golpe da maioridade, bem como aqueles que cercaram os projetos da lei de Interpretação do Ato adicional de 1834 (1840), o de reforma do Código de Processo Criminal e o de recriação do Conselho de Estado, ambos em 1841. Ver, entre outros, MARTINS, Maria Fernanda Vieira. A velha arte de governar: um estudo sobre política e elites a partir do Conselho de Estado (1842-1889). Rio de Janeiro: Arquivo Nacional, 2007; GOUVEIA, Maria de Fátima. O Império das Províncias. Rio de Janeiro: Civilização Brasileira, 2008; VELLASCO, Ivan de Andrade. As seduções da Ordem: Violência, Criminalidade e Administração da Justiça de Minas Gerais, Século 19. Bauru I São Paulo: Edusc / ANPOCS, 2004. regular (1868 - 1889) e concorreram para a manutenção e sobrevivência de uma instituição que condenava diretamente os métodos de cultivo no vale e o emprego da mão de obra escrava, considerados símbolos do atraso e estagnação da agricultura fluminense.

Não gostaria de me alongar nessa história, mas o que mais surpreendeu na pesquisa foi perceber, através da análise dos inventários, negócios e investimentos dos membros da instituição, a presença de mentalidades distintas entre os fazendeiros do vale, constatando-se que alguns já diversificavam suas atividades econômicas ao menos desde a década de 1860, basicamente aqueles que se mantiveram nos cargos diretores da instituição. Esses casos devem ser descartados como periféricos ou irrelevantes? São fenômenos isolados ou reflexos de uma realidade muito mais complexa e dinâmica do que imaginávamos a princípio?

Há ainda duas outras questões que considero importante comentar. Primeiramente, a indicação do esvaziamento do debate político, que esvazia a própria autonomia de um campo da política. Diante do aniquilamento dos chamados liberais em 1842, como o autor afirma (a expressão utilizada é processo histórico de subordinação política), como explicar as tensões do regime, o calor dos debates, as questões eleitorais, as disputas por nomeações, as discussões em torno da carta constitucional, do modelo econômico e da politica monetária, as críticas recorrentes no Parlamento e na imprensa, que se avolumam a partir dos anos de 1850 ?

Não creio que os liberais tenham sido subordinados. Após a derrota do movimento mineiro de 1842, por exemplo, o governo imperial correu para anistiar suas lideranças. Em poucos anos, estavam quase todos no Conselho de Estado, onde, ao contrário do que se imagina, enfrentaram coerentemente - com frequência ombro a ombro - os conservadores ortodoxos, particularmente nos debates, projetos e pareceres ligados a questões importantes de sua agenda, tal como o funcionamento do judiciário, a autonomia provincial, o equilibrio entre os poderes, a política fiscal e monetária etc. Mesmo assim, não creio que ali a questão fosse a oposição entre conservadores e liberais, pois o Conselho era um fórum privilegiado para a discussão da governabilidade.

Aqui abro outro parêntese para comentar questão aparentemente formal, mas que revela muito sobre as opções de abordagem do artigo - a escolha do corte cronológico inicial. A escolha também não parece justificada consistentemente, pois evita o corte tradicional do início do II Reinado, 1840, e parte da utilização do ano de 1847, ano de criação da Presidência de Gabinete, sem considerar a questão política fundamental que essa mudança representa, porque ela, em si, não é analisada. A justificativa não se dá em torno dos possiveis significados que envolvem a criação da nova instância do Executivo, a Presidência de Gabinete, mas como uma espécie de marco da consolidação e estabilidade do chamado poder conservador. Entretanto, o importante a ressaltar é que essa opção exclui, convenientemente, todo o debate e as tensões políticas que fundaram o II Reinado e contribuiram diretamente para a eclosão dos movimentos revoltosos de 1842. Considerar a autonomia do campo da política é também, nesse caso específico, levar em conta o quanto essas disputas e embates influenciaram e moldaram a ação daqueles que assumiriam os principais quadros do Executivo a partir de então. ${ }^{10}$

Isso nos leva à segunda questão, que é o problema das províncias. Não vejo o Estado imperial (ou qualquer outro) como representação ou 
11

Com relação à importância da dinâmica da vida política e econômica provincial, bem como da atuação e comportamento de elites e instâncias de poder regional, tanto no período colonial como no imperial, ver dentre outros GOUVEIA, Maria de Fátima. 0 Império das Províncias. Op. Cit.; FRAGOSO, João Luis Ribeiro; ALMEIDA, Carla Maria Carvalho de; SAMPAIO, Antonio Carlos Jucá de. (orgs.). Conquistadores e negociantes: Histórias de elites no Antigo Regime nos trópicos. América lusa, séculos XVI a XVIII. Rio de Janeiro: Civilização Brasileira, 2007; GIL, Tiago Luís. Infiéis transgressores: elites e contrabandistas nas fronteiras do Rio Grande e do Rio Pardo (1760-1810). Rio de Janeiro: Arquivo Nacional, 2007; ANDRADE, Marcos Ferreira. Elites regionais e a formação do estado imperial brasileiro: Minas Gerais - Campanha da Princesa (1799-1850). Rio de Janeiro: Arquivo Nacional, 2008; DOLHNIKOFF Miriam. 0 Pacto Imperial: origens do federalismo no Brasil do século XIX. São Paulo: Globo, 2005; Além de autores aqui já mencionados, cito especificamente os excelentes trabalhos de FARINATTI, Luis Augusto. Confins Meridionais: familias de elite e sociedade agrária na fronteira sul do Brasil (1825-1865). Santa Maria: Editora da UFSM, 2010 e de VARGAS, Jonas Moreira. Entre a Paróquia e a Corte. Os mediadores e as estratégias familiares da elite política do Rio Grande do Sul (1850-1889). Santa Maria: Editora da UFSM/ANPUH, 2010. hegemonia de uma classe ou de um estamento burocrático. Não o vejo também dissociado de suas origens históricas. Vejo-o como resultante de relações, interações e negociações permanentes e cotidianas em uma dada sociedade, na busca de legitimidade, estabilidade e governabilidade.

Portanto, precisamos nos atentar para a necessidade desse Estado se legitimar diante dos poderes tradicionais, enraizados nas diferentes províncias, vilas e cidades. Esse processo não apresenta direção única, do centro para as províncias, nem pode se dar da noite para o dia. A vida política provincial e local, sua dinâmica e autonomia, suas estruturas de mando, suas redes comerciais e políticas, antecedem em muito a ascensão dessa chamada classe senhorial. Nada disso desapareceu instantaneamente, como demonstram os esforços cada vez mais intensos da centralização, por parte do governo imperial. Nunca será excessivo lembrar que o Brasil enfrentou suas guerras de independência, bem como diferenciados e acirrados conflitos provinciais desde o I reinado e ao longo do período regencial, que ameaçaram seriamente a integridade do Império.

Nesse sentido, como entender essa ação demiúrgica de uma classe? Como essa moral escravista e proprietária se impôs sobre grupos tão diferenciados e heterogêneos, que notoriamente se digladiavam em diversas e variáveis arenas e conjunturas? Por que a direção de uma classe específica é aceita de norte ao sul do pais, por elites de fronteira, pelos comerciantes do norte, pelos estancieiros do sul, pelos chamados capitalistas e interesses financeiros, pelos grandes comerciantes ligados ao mercado interno e pelos poderes locais e provinciais? Isso se nos ativermos ao âmbito das elites.

0 Império não é o Rio de Janeiro e não se explica por ele. Mesmo deixando de lado o período colonial, é fato que, depois de 1824, a vida política provincial se adensou e se dinamizou ainda mais, em razão dos espaços de debate público criados, da ampliação, ainda que em nivel restrito, da representação, dos alinhamentos, dos conflitos históricos e disputas em torno dos novos cargos e instâncias administrativas regionais.

$\mathrm{Na}$ verdade, creio que não vamos conseguir analisar efetivamente a formação desse Estado sem o desenvolvimento dos estudos provinciais. No meu entender, é exatamente a importância e a dimensão dessa dinâmica política local e dessas províncias que nos permite compreender os esforços no sentido da centralização, particularmente as diferenciadas e permanentes estratégias de consolidação de um poder central para que seja reconhecido, de alguma forma, como legítimo. ${ }^{11}$

Portanto, ainda precisamos saber quem são essas elites locais, como atuaram, quais eram os alinhamentos políticos e os projetos específicos que se desenvolviam e se debatiam nos diferentes órgãos e autoridades provinciais - as juntas governativas, os conselhos gerais de governo e de província, os eleitores, as câmaras, as assembleias provinciais.

Para avançarmos nesse debate, creio, a historiografia brasileira precisa abandonar essa tradicional visão das províncias como áreas periféricas e conceder à dinâmica política regional o seu devido protagonismo, particularmente naqueles momentos em que esteve em jogo a afirmação da autoridade central e a consolidação da unidade territorial. Trata-se, portanto, de reavaliar e encontrar o lugar daquelas já mencionadas bordas e lacunas que são excluídas ou tratadas como residuais, irrelevantes e isoladas em proveito da utilização de um dado modelo teórico, mas que precisa efetivamente dar conta e incorporar as novidades que vão surgindo quanto mais se desenvolve a pesquisa no âmbito regional. 
GRAHAN, Richard. Construindo uma nação no Brasil do século XIX: visões novas e antigas sobre classe, cultura e Estado. Diálogo, UEM, v.05, n.01, 2001. Disponivel em: http://www.dialogos.uem.br/

Abordei a questão das transformações de comportamento das elites fluminenses entre o final do século XVIII e meados do XIX em MARTINS, Maria Fernanda. Os tempos da mudança: elites, poder e redes familiares no Brasil, séculos XVIII e XIX. FRAGOSO, João Luis Ribeiro; ALMEIDA, Carla Maria Carvalho de; SAMPAIO, Antonio Carlos Jucá de. (orgs.) Conquistadores e negociantes, $0 \mathrm{p}$. Cit.

Segundo Chales Tilly, a centralização do poder englobaria a unificação e consolidação das fronteiras territoriais; a superação de conflitos via controle de poderes paralelos e manutenção de hierarquias sociais pré-estabelecidas; a constituição de um aparato jurídico visando a normatização de sua ação legal; a formação de uma estrutura burocrática para garantir a administração; e a transferência dos serviços básicos do poder privado para o poder público, aspectos que, em conjunto, possibilitam a construção de uma autoridade central. Ver TILLY, Charles. Coerção, capital e estados europeus, 1990-1992, cap.1; e TILLY, Charles. Reflections on the history of european state-making. In: (org). The formation of national States in Western Europe. Princeton: Princeton University Press, 1975. p.74-75

15

GRAHAN, Richard. Construindo uma nação no Brasil do século XIX, Op. Cit.

Recebido para publicação em agosto de 2012 Aprovado em agosto de 2012
Por fim, em princípio tendo a concordar com o historiador Richard Graham quando afirma que homens ricos através de todo o Brasil jogaram nas novas instituições, não porque tivessem sido encantados por um discurso hegemônico, mas porque tinham interesses imediatos a proteger..$^{12}$ São coisas muito distintas. Mais uma vez, trata-se de diferentes racionalidades.

De fato, entendo a história como mudança. Mas é preciso reconhecer que muitas coisas permanecem, mesmo quando mudam. Determinados hábitos, comportamentos, mentalidades e práticas culturais, seja no âmbito da ação política, social ou econômica, tendem a se manter no tempo e só começam a se transformar em longo prazo. Conservar é, em diversos sentidos, diminuir riscos e garantir segurança, ao menos enquanto isso é possível. Quando se fala na continuidade de determinados grupos e famílias e de suas redes de alianças no poder não se está afirmando a preponderância de alianças e práticas clientelares que se justificam por elas mesmas; elas são os meios e não os fins da ação política. Muito menos se está negando a mudança, mas se reconhecendo que, para se manterem como elites, esses grupos precisaram mudar e se adequar a novas conjunturas e realidades. Com esse objetivo, lançaram mão de estratégias, fizeram planos e escolhas que, inclusive, nem sempre foram bem sucedidas. Agiram, portanto, de acordo com suas interpretações das conjunturas, de seus cálculos e suas projeções de futuro, seguindo suas racionalidades. ${ }^{13}$

Quanto aos grupos que alcançaram a cúpula do poder no Brasil imperial, tais escolhas, planos e projetos não puderam se manter exclusivamente no nivel dos interesses pessoais ou das práticas políticas herdadas do período colonial; fez-se necessário conciliar diferentes tendências e heranças. Tais interesses precisaram se adequar a uma nova ordem, sob influência do ideário liberal europeu, que impunha a necessidade de se considerar novas razões para sua atuação politica e econômica, as chamadas razões de estado, pois o que efetivamente se encontrava em curso era a construção de um novo espaço do público. A atenção a essa nova instância encontra-se na base das reformas empreendidas pelo governo imperial e suas lideranças, particularmente aquelas que visavam a monopolização do poder de coerção e Justiça e o controle da administração pública no caminho para a construção de uma autoridade central legítima e para o que Charles Tilly chamou de transição para um governo direto. ${ }^{14}$

Para concluir, também é Richard Graham que enuncia uma frase que cito por crer que resume muito do que comporta essa exposição: Certamente, precisamos preencher o esqueleto teórico, tanto do Estado quanto da nação, e focalizar os processos, bem como os resultados ${ }^{15}$. 